\title{
First Responder/Private Industry Collaboration to Advance Disaster Response
}

\author{
M. Shaurette and R. R. Rapp \\ Department of Building Construction Management, Purdue University \\ T. R. Stahr \\ Senior Consultant, Environmental Resources Management
}

\begin{abstract}
In most developed countries, well-established communities of first responder organizations have formed to provide a quick and coordinated reaction to disasters. In most cases these response organizations are controlled, organized, and funded by related governmental agencies. Because their disaster response contributes to the good of the public, the existence of government funded and coordinated first responder organizations are considered by many to be the most effective approach to provide disaster response. Unfortunately, these organizations do not always have ready access to all of the skills and resources required to efficiently respond to many of the physical challenges that result from wide-ranging disasters.

This paper provides a description of some of the resources and skills possessed by private demolition and disaster response companies that could be made available for widespread disaster response. If properly coordinated prior to a major disaster, these private organizations could be called upon to collaborate with first responders. Coordination challenges that commonly prevent first responder/private industry collaboration after widespread disasters are presented along with several examples of successful partnerships.
\end{abstract}

Keywords: demolition, restoration, collaboration, second-responder, private-industry

\section{INTRODUCTION}

The valuable service of first responders is well known, but they commonly lack the equipment and expertise of specialty construction contractors. Demolition and disaster response contractors have equipment, resources, and skill sets that simply do not exist within first responder organizations. First responders typically do not have the ability to mobilize the most appropriate resources in every location required on short notice. While the financial resources of many first response organizations are substantial, it is difficult to mobilize such complex organizational and physical responses quickly and effectively.

Disasters occur throughout the world. It is impossible for any first response organization to have adequate equipment and resources staged across such a vast territory. Local disaster response organizations are better distributed to deal with disasters, but their physical resources are not normally adequate to respond to a major disaster. Specialty contractors are more geographically dispersed.

Mere familiarity with equipment is not enough to properly plan its application. Equipment technologies improve almost annually. Private organizations are more likely than first responder organizations to have both the up-to-date technologies and skills to properly utilize it. In addition, the logistical challenges of moving equipment resources over long distances and impeded routes within major regional disaster zones cannot be appreciated until confronted.

Furthermore, many first responders do not understand the business and contractual issues that might keep contractors from participating in rescue operations. Failing to address those needs during planning will not get the right contractors to where they are needed. Channels of communication, both technological and managerial, often do not include the contractor community. Contractors generally wish to work directly for the first responder command and not through intermediaries. They want a single point of contact for information up and down the responding supervisory chain. Contractors must know that their reasonable emergency efforts will not create legal liability if those efforts result in further injury or damage. As with all operations, there must be a clear assignment of tasks and responsibilities without confusing and delaying overlaps or gaps. If a municipality must first obtain authorization to assure reimbursement from state or federal agencies, they should do so before the specialty contractor starts work. 
Contractors have their challenges, as well. Safety issues commonly include sharp, broken structural elements; rampant pathogens, disease transmission vectors, and vermin; long hours with little rest; poor food and little water; and inadequate personal and asset security. Utilities might be unavailable, thus further burdening logistical systems. Dealing with distraught victims can be harrowing.

For a number of reasons, contractors also face uncertain payment for their disaster response work. Examples include cases when owners cannot pay insurance policy deductibles, leaving contractors to carry more financial risk, or when contractual requirements include terms which impose high-risk conditions on the contractor. These high-risk conditions are frequently called "killer clauses" or "murder clauses." These risks alone may dissuade the contractor from beginning work. They may also need record drawings of damaged facilities to ensure quick, proper demolition and restoration. Contractors can face resentment from locals who dislike "outsiders" getting work and earning money off local misfortune when the local organizations think they can do the work just as well. Larger, distant contractors might have the wherewithal to organize larger response efforts, but local contractors may be prepared for a more timely response. Politicians and others prefer lump-sum contracts for all work, so optimum contractual risk allocation may be elusive without prearranged agreements with private firms participating in disaster response.

\section{LITERATURE REVIEW}

The array of specialized contractor equipment that can be useful for immediate disaster response may not be known by all emergency managers and public or private owners. As but one example, better access and reduced safety risk results from remotely controlled demolition robots in common use by the demolition industry (Figure 1).

Fitted with hydraulic breakers and other attachments, track-based, electrically powered demolition robots can venture into interiors, hazardous environments, and confined spaces to dismantle floors, ceilings, and wall slabs, keeping workers out of the way of falling concrete and other dangers. (Parsons, 2011)

Knowing the capabilities that are available is important. Integrating them into planned operations is also necessary. A study of Hurricane Katrina confirms that it is inappropriate to await a disaster to integrate essential capabilities into a synergistic plan of response. "Overwhelmed during a crisis and unfamiliar with emergent actors, incident commanders lack the time to learn what emergent capacities are on offer." (Moynihan, 2009 p. 902)

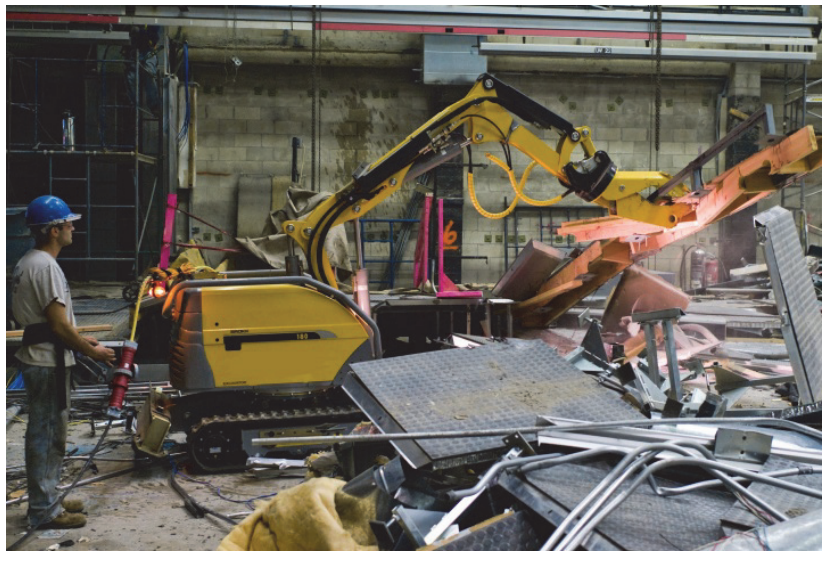

Figure 1. Remotely controlled demolition equipment

With so much happening so quickly when disaster strikes, the typical emergency response organization and public or private owners will probably feel overwhelmed. Laying the groundwork before trouble strikes is imperative. From their wide experience in disaster response, the U.S. Army Corps of Engineers "...uses pre-awarded contracts that can be quickly activated for missions such as water, ice, temporary roofing, generator installation, and debris management." (USACE, n.d.) The imperatives that compel advance agreements for the more common commodities and services lead one to conclude that quick and effective action from construction specialty contractors might also be secured with preagreements or preawarded contracts.

Good communication systems are another critical factor for the best specialty contractor response. More than hardware alone, the right people and processes are essential for prompt and effective disaster response. The system of communicating vital information when a disaster strikes is commonly compromised for reasons beyond physical capabilities. "But our response professionals pointed to an unwillingness to agree to a shared system, a lack of commitment to operate using this system, and a lack of discipline to use it correctly." (Donahue \& Tuohy, 2006)

It is prudent to apply mechanisms that reduce the need to communicate or enhance the communication that must occur in order to obtain the essential response in the first critical hours of a disaster. One approach is to employ training exercises as part of preagreements. These exercises can better inform emergency managers and contractors of what the other party will require. Including contractors in these training activities would build the personal familiarity so crucial to engendering trustful teamwork and would offer a means to improve or make more obvious some of the communications that are otherwise required. Contractors providing unique capabilities must be included in such planning discussions and exercises 
by public and private owners if the risk of slow or inappropriate response is to be reduced.

Both commercial business owners and government entities can benefit from appropriate preagreements. The Federal Acquisition Regulation (FAR) specifies terms that must be followed for advance agreements (FAR 31.109). Although complex and imperfectly applicable, the Federal Acquisition Regulation (FAR) can guide states, municipalities, and commercial owners to address a wide array of contractingrelated issues. Where U.S. Government (USG) funds are to be directly obligated under costreimbursement contracts-with payment terms not uncommon for uncertain work scope-prenegotiation before any costs are incurred by disaster responding contractors would be appropriate [FAR 31.109(b)]. For any funding reimbursement by the USG, all such costs must be allowable, allocable, and reasonable. A number of the 17 special cost categories for costreimbursement contracts should draw special attention during prenegotiations with construction industry contractors. Among them are: (1) construction equipment cost, especially fully depreciated assets, idle time, and mobilization or demobilization; (2) company general and administrative (G\&A) cost share; (3) per diem rates; and (4) professional services [FAR 31.109(h)].

\section{POTENTIAL FOR COLLABORATION}

Private entities that are actively engaged in demolition and disaster restoration are well qualified to augment the resources of the first responders by acting in a "second responder" role. While there does not appear to be a well-developed definition of "second responder," the term is defined for this paper as "an organized contractor under the command and control of a first responder." For this relationship to be most effectively implemented, the contractor's services should be defined and contracted for before the disaster.

The advanced planning model proposed in this paper could be adapted to address any number of disaster-related issues, such as supplying fuel and food supplies, removal of damaged structures, waste removal, stabilizing damaged structures, or implementing initial building or infrastructure restoration to minimize structural or surface damage to mention just a few. It is theorized that developing contractual agreements in advance will be more economical than waiting until after the disaster has occurred. In addition, involving experienced contractors and their employees in disaster planning will increase awareness within the general population of disaster threats and how to deal with them.

Demolition contractors along with their allied vendors have the equipment and the expertise to assist with

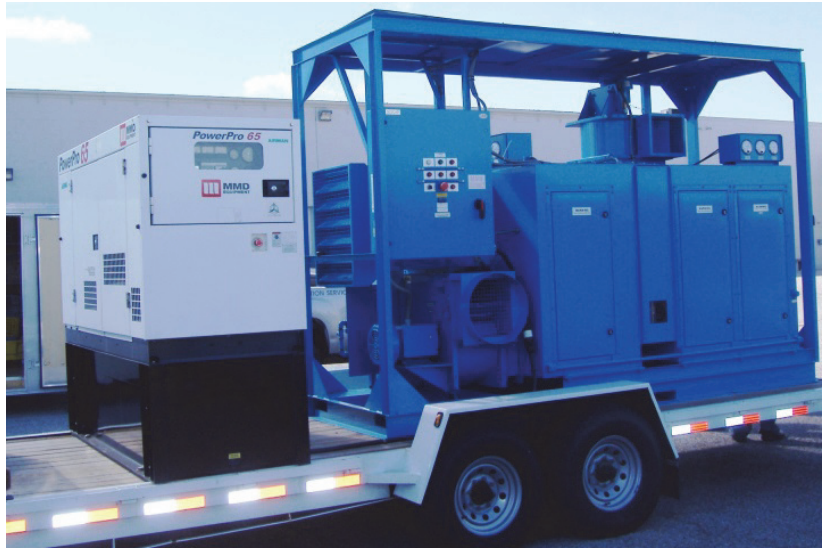

Figure 2. Trailer-mounted desiccant dehumidifier

many of the transportation-related aspects of disaster response. These contractors are accustomed to the challenges of controlling traffic on a temporary basis in high-volume environments such as urban areas. They also have the ability to quickly complete temporary repairs to damaged roadways or to provide temporary gravel lanes around obstacles. Through the use of prestaged barriers and barricades, these contractors could quickly mobilize to delineate evacuation routes and to block off appropriate entrance and exit ramps to develop contra-flow traffic.

Demolition contractors also have the equipment and skills necessary to quickly clear obstacles to safe and successful evacuation and/or re-entry of impacted areas. Obstacles include damaged buildings; collapsed or partially collapsed overpasses or bridges; and severely damaged pavement that can result from fire, seismic action, and flooding. In each case, demolition contractors can be an invaluable second responder to assist first responders in search and rescue missions where damaged or collapsed structures are involved. The concepts elaborated herein could be applied to restoration contractors as well. The specialized forms of equipment (Figure 2) and skills employed by these contractors are typically not possessed by first responder organizations.

As the fire and water restoration subsector of the construction industry has matured, contractors and owners have expanded their use of preagreements to benefit of both parties. By using preagreements, owners reduce their risk of being unable to find a fully competent contractor to restore their structures and contents after a disaster. Contractors know the kinds and amounts of work they will encounter if major disasters of assorted types strike, allowing them to launch more effective preparation and response. Of course, even with the advantages of a preagreement, the parties should follow through by signing a contract outlining contractual terms and 
conditions as soon as possible. Ultimately, no documentation fully replaces a proper contract.

Fuel suppliers and food warehouses could also participate to prearrange making their inventory available at pre-established prices in the event of a disaster. This approach would make the most of fuel and food resources already existing in close proximity to areas affected by the disaster or the evacuation.

\section{COMPONENTS OF COOPERATION AGREEMENTS}

The key elements of any cooperative agreements have been suggested during discussion of homeland security preparation (Behling, Orczyk, \& Shaurette, 2007). The elements suggested include:

- Government entities responsible for first response must contract with private contractors in advance of a disaster.

- Contractors are under the command and control of first responders.

- Contractors are reimbursed on an hourly basis for labor and equipment at predetermined rates.

- Contractors are reimbursed for materials consumed.

- Contractors are afforded liability protections.

In order to minimize the reluctance of contractors to participate from a risk-management perspective, it will be necessary to provide indemnification to the contractors participating in the disaster response. This should be a logical step because the second responders will be acting under the direction of first responder groups (typically government agencies) who may already enjoy some immunity in the execution of their response to the disaster. Contractual provisions should be made to underscore that the contractors are working for the first responder as an extension of their resources.

Preplanning will require anticipation of numerous indefinite details. Because it is impossible to fully predict what work may be needed to facilitate a disaster response, it is suggested that the scope of work be limited to provision for labor and equipment on an hourly basis. It is paramount that contractors be confident that they will be fairly and justly compensated for their contributions. While some contractors may be willing to absorb a "donation" of labor and equipment to what many would view as a humanitarian effort, most will be unable to risk their livelihood to assist in a disaster response.

One lesson learned from 9/11 was that the New York City Fire Department and Police Department had difficulties communicating with each other. In order to be effective, communication strategies will need to be established to connect the first responders to each contractor or supplier involved. Specific approaches to addressing this challenge are beyond the scope of this paper but are nonetheless important to consider.

It is important to put into place assurances that contractors assisting first responders can execute their duties and not place their own families at risk by doing so. Therefore, a program to reassure responders that their loved ones are being protected must be part of a well thought out disaster response plan.

To avoid disputes over reimbursement to contractors for expenditures incurred, advance disaster response agreements must anticipate all of the costs incurred by a contractor working in cooperation with a first responder. It is important that contractors get paid for any equipment that is summoned by the first responders but not directly placed into service. This mobilization and lost productive time reimbursement should be in addition to labor, materials, and equipment actually consumed. Job order and timesheet forms should be developed to accurately track equipment and labor mobilized as well as how much of it is actually used. The National Demolition Association has been active in developing model agreements between local fire departments and demolition contractors including what amounts to a work authorization form. These model agreements clarify the following critical issues:

- Who will pay the contractor for their work?

- Who will direct the contractor in their work?

- Unit pricing for all labor and equipment both brought to and/or used on the site or to support the work at the site (e.g., equipment mechanics, industrial hygienists, medical monitoring costs, etc.).

- Liability assumed by the contractor.

- When the contractor's service and the terms under which they are performing for the public body are considered complete.

- Any minimums or limits to the number of men, or the types and number of equipment a contractor is committed to provide.

- Any timeframes under which the contractor is expected to mobilize and perform the work.

Contractors participating in the disaster response will incur home office management costs to support whatever is done in the field. Contractors should be allowed to recoup their general and administrative 
costs through an overhead charge. Profit should also be allowed to help offset the lost opportunity cost of not having their resources employed in a for-profit project.

Appropriate postdisaster restoration activity is important to accelerating the rebound from any disaster event. Through quick action shortly following a disaster, property losses can be substantially minimized. It may be economically advantageous to contract in advance for these services when the rush and stress of crisis or postcrisis is not pressing. Time is especially of the essence to mitigate damage ensuing from water and fire losses accompanying many disaster-spawned perils. Appropriate dry-out of structures and materials enables them to be restored in situ instead of being demolished and reinstalled anew. Mold may begin its destructive and unhealthy activity within 72 hours after organic construction materials become damp. Smoke residues create acids in a wet environment, so quickly neutralizing and removing them before they can destroy structures and personal property is imperative.

\section{SUCCESSFUL COLLABORATION}

Basic demolition incidental to property restoration tasks is often in the purview of restoration contractors. Indeed, part of the Building Systems Restoration Strategy section of the soon-to-bepublished Restoration Industry Association Certified Restorer ${ }^{\circledR}$ Body of Knowledge (Restoration Industry Association, 2014) comprises demolition equipment and processes. However, when larger and more complex jobs emerge, the experience of many owners shows that a demolition contractor should be hired.

Demolition and restoration companies often combine their knowledge and expertise to provide safe and efficient decontamination and demolition after all types and sizes of disasters from single-family home fires to widespread hurricane, fire, and flood damage.

The LaSalle Bank Building was cleaned and the interior of the building stripped by an experienced team of demolition and restoration companies after a massive fire in Chicago in April 2012. A number of serious health and safety issues were successfully overcome by the team, including lead contamination and an unstable structure.

After the closure of a large pharmaceutical plant in Spain, two of the world's largest restoration and demolition companies combined their efforts to remediate and remove several large contaminated structures.

In Japan, following the Tohoku earthquake in 2011, cooperation between restoration companies and demolition companies enabled the country to begin the massive effort necessary to restore the area to a habitable condition.

\section{SUMMARY AND CONCLUSION}

Contractor/first responder collaboration is needed because the combined assets of first responder agencies do not generally have the geographic diversity, resources, and expertise to provide the services that contractors can quickly provide. In a moment of crisis, it is crucial to have the right people with the right equipment in the right location. Employing contractors in the disaster response can meet all three needs.

In order to be successful, an effective contractor/first responder collaboration must include advanced agreements which provide liability protection for contractors and assurances for fair compensation. This includes smaller contractors who are geographically positioned to help during the disaster. In addition, the human element should be addressed with a plan to care for the families of the first and second responders during any time of crisis.

\section{REFERENCES}

Behling, K., Orczyk, J., \& Shaurette, M. (2007). The civilian construction contractor corps. Paper presented at the Homeland Security: The ripple effect conference, Washington, D.C.

Donahue, A. K., \& Tuohy, R. V. (July 2006) Lessons we don't learn: A study of the lessons of disasters, why we repeat them, and how we can learn them. Homeland Security Affairs, 2(2), 7. Retrieved from http://www.hsaj.org/?article=2.2.4

Federal Acquisition Regulation. (January 2014). 31.109 Advance agreements. Retrieved from https://acquisition.gov/far/current/html/Subpart $\% 20$ 31_1.html\#wp1089616

Moynihan, D. P. (2009). The network governance of crisis response: Case studies of incident command systems. Journal of Public Administration Research and Theory, 19(4), 895-915. http://dx.doi.org/ 10.1093/jopart/mun033

Parsons, J. (2011, March 2). Demolition robots break new ground. Retrieved from http://enr.construction. com/products/equipment/2011/0302-

DemolitionRobots.asp

Restoration Industry Association. (2014). Certified restorer curriculum [Unpublished revision of April 4]. Rockville, MD: Restoration Industry Association.

U.S. Army Corps of Engineers. (n.d.). Emergency response. Retrieved from http://www.usace.army. mil/Media/FactSheets/FactSheetArticleView/tabid/2 19/Article/475476/emergency-response.aspx 